\title{
Thermal Aging Behaviors of Weather Resistant Rubber Composites of EPDM, IIR, and BIIR
}

\author{
Sung-Seen $\mathrm{Choi}^{\dagger}$ and Jong-Chul Kim \\ Department of Chemistry, Sejong University, 98 Gunja-dong, Gwangjin-gu, \\ Seoul 143-747, Korea
}

(Received March 21, 2012, Revised April 27, 2012, May 30, Accepted May 31, 2012)

\section{$\mathrm{EPDM}, \mathrm{IIR}$, 그리고 BIIR 내후성 고무 복합체의 열노화 거동}

\author{
최성신 ${ }^{\dagger}$ 김종철 \\ 세종대학교 화학과 \\ 접수일(2012년 3월 21일), 수정일(1차: 2012년 4월 27일, 2차:5월 30일), 게재확정일(2012년 5월 31일)
}

\begin{abstract}
EPDM, IIR, and BIIR composites were thermally aged and the crosslink density changes were investigated. Crosslink densities of the EPDM composite increased with increasing the aging time and temperature, whereas those of IIR and BIIR composites for long-term aging at high temperatures tended to decrease. Activation energies for the crosslink density changes of the EPDM composite were higher than those of the BIIR one. The experimental results were explained with the number of allylic hydrogens, activation of the zinc complex, the steric hindrance effect, and oxidation of rubber chain.

요 약 : EPDM, IIR, 그리고 BIIR 복합체를 열노화시켜 가교밀도 변화를 조사하였다. 노화 시간이 증가하거나 노화 온도가 올라갈수록 $\mathrm{EPDM}$ 복합체의 가교밀도는 증가하였으나, 고온에서 장기간 노화된 IIR과 BIIR 복합체의 가교밀도 는 감소하는 경향을 보였다. $\mathrm{EPDM}$ 복합체의 가교밀도 변화에 대한 활성화 에너지는 BIIR 복합체보다 높았다. 실험 결과는 알릴 수소의 수, 아연 복합체의 활성화, 입체 가리움 효과, 그리고 고무 사슬의 산화로 설명하였다.
\end{abstract}

Keywords : thermal aging; EPDM; IIR; BIIR; crosslink density change; activation energy

\section{I . Introduction}

$\mathrm{R}$ group rubbers such as natural rubber (NR), butadiene rubber (BR), styrene-butadiene rubber (SBR), and acrylonitrilebutadiene rubber $(\mathrm{NBR})$ have unsaturated hydrocarbon $(\mathrm{C}=\mathrm{C}$ double bond) backbones. Due to the $\mathrm{C}=\mathrm{C}$ double bond backbones, they have lots of allylic hydrogens which participate in sulfur crosslinking reaction. ${ }^{1}$ Hence, degrees of crosslink density changes of the $\mathrm{R}$ group rubber composites by themal aging are relatively high, and their physical and chemical properties are also changed. ${ }^{2-10}$ Of $\mathrm{R}$ group rubbers, isobutene-isoprene rubber (butyl rubber, IIR) has relatively good thermal resistance properties since it has only isoprene content with less than $3 \mathrm{wt} \%{ }^{11,12}$

Crosslink type and degree of crosslink density of a rubber vulcanizate determine the physical properties such as modulus, hardness, resilience, elongation at break, heat build-up, and so forth. ${ }^{13}$ Sulfide linkages, especially polysulfides, are dis-

\footnotetext{
${ }^{\dagger}$ Corresponding Author. E-mail: sschoi@sejong.ac.kr
}

sociated by heating ${ }^{14,15}$ and this brings about decrease of the crosslink density. Curatives, especially sulfur, in rubber vulcanizates make new crosslinks ${ }^{16}$ and this results in increase of the crosslink density. Crosslink density of a rubber vulcanizate is changed by thermal aging. ${ }^{4,17-20}$ In general, when sulfur-cured rubber vulcanizates are thermally aged, the crosslink densities increase and the degree also increases as the aging temperature and time increase. ${ }^{21-23}$ Crosslink density change by thermal aging is also one of reasons about permanent deformation of a rubber vulcanizate. ${ }^{21-23}$

Brown and coworkers reported physical property changes of rubber composites after natural aging for 40 years and compared with the accelerated heat aging results. ${ }^{24,25}$ Relative deviations for the physical property changes of naturally aged rubber vulcanizates were very big but the results were valuable. The big deviation of the physical property may be due to the difference in the initial states of the samples. A number of samples are needed to measure physical properties and to perform thermal aging for a long time. Sample size should be small to minimize the experimental errors, but relatively large sample size for measurement of the physical properties should 
be required. Sample dimension for measurement of the crosslink density is less than $1 \mathrm{~cm} \times 1 \mathrm{~cm}$. Thus, experimental errors for thermal aging behaviors of a rubber article can be reduced by measuring the crosslink density changes not the physical property changes.

In this work, we studied thermal aging behaviors of weather-resistant rubber composites such as ethylene-propylene-diene rubber (EPDM), IIR, and brominated isobutene-isoprene rubber (bromobutyl rubber, BIIR) by measuring their crosslink density changes. Thermal aging was performed for $2-185$ days in a convection oven and the thermal aging behaviors were investigated by dividing into short- and long-term aging results. Activation energy for the crosslink density change by thermal aging was obtained from Arrhenius plot and the variation with the aging time was also investigated to characterize their thermal aging behaviors. EPDM grade is determined by the contents of ethylene, propylene, and diene as well as the kind of diene. IIR and BIIR grades are determined depending on the isoprene content. Scheme 1 shows general chemical structures of EPDM, IIR, and BIIR. EPDM has outstanding properties for heat, ozone, and weather resistances as well as resistance to polar substances. Since it has also excellent elec-
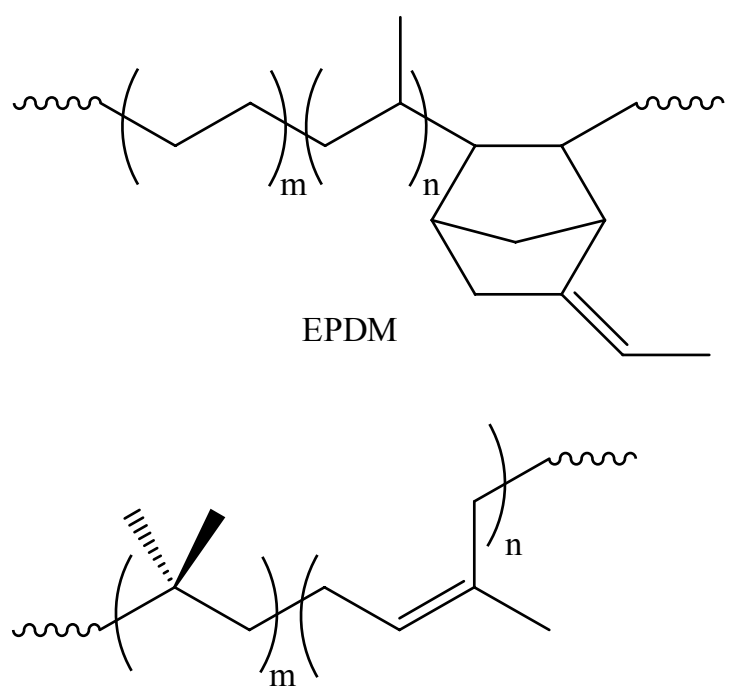

IIR

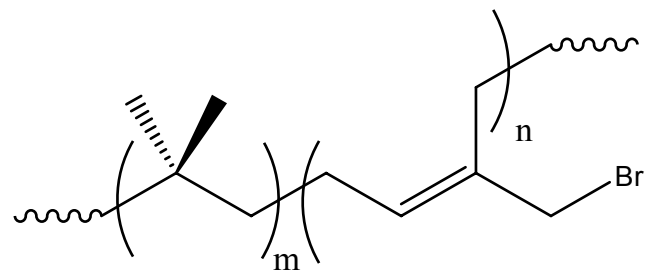

BIIR trical properties, it is widely used in electrical insulations. IIR has some properties similar to those of EPDM, such as good weather resistance ${ }^{5,26}$ and good mineral acid and base resistance. Since IIR has also excellent resistance to permeability by gases, it is significantly used in curing bladders and inner tubes for tires. If a halogen (chlorine or bromine) is introduced into IIR, it becomes halobutyl rubbers such as CIIR or BIIR, respectively.

\section{Experimental}

Carbon black-reinforced EPDM, IIR, and BIIR compounds were made of rubber (EPDM, IIR, or BIIR $100.0 \mathrm{phr}$ ), carbon black (N220 $50.0 \mathrm{phr}$ ), antidegradants ( $N$-phenyl- $N$-(1,3-dimethylbutyl)-p-phenylenediamine (HPPD) $2.0 \mathrm{phr}$ and wax 2.0 phr), cure activators (stearic acid $2.0 \mathrm{phr}$ and $\mathrm{ZnO} 2.0 \mathrm{phr}$ ), $N$-tert-butyl-2-benzothiazole sulfenamide (TBBS, $1.4 \mathrm{phr}$ ), and sulfur (1.4 phr). KEP 350 (ethylidene norbornene (ENB) content $=8 \mathrm{wt} \%$ ) of Kumho Polychemical Co., Butyl 268 (isoprene content $=1.7 \mathrm{~mol} \%$ ) of Exxon Chemical Co., and Bromobutyl 2222 (functional bromine content $=1.03 \mathrm{~mol} \%$ ) of Exxon Chemical Co. were employed as EPDM, IIR, and BIIR, respectively. Mixing was performed in a Banbury type mixer at a rotor speed of 45 and $30 \mathrm{rpm}$ for master batch (MB) and final mixing (FM) stages, respectively. The initial temperatures of the mixer were 110 and $80{ }^{\circ} \mathrm{C}$ for $\mathrm{MB}$ and FM stages, respectively. The MB compounds were prepared as follow. (1) The rubber was loaded into the mixer and preheated for $0.5 \mathrm{~min}$. (2) The carbon black was compounded into the rubber for $2.0 \mathrm{~min}$. (3) The antidegradants and cure activators were mixed for $2.0 \mathrm{~min}$ and the compounds were discharged. The FM compounds were prepared by mixing the sulfur and TBBS with the MB compounds for $2.0 \mathrm{~min}$. The vulcanizates were prepared by curing at $160{ }^{\circ} \mathrm{C}$ for $30 \mathrm{~min}$ in a compression mold $(140 \mathrm{~mm} \times 140 \mathrm{~mm} \times 2 \mathrm{~mm})$.

The sample dimension for the thermal aging experiment was $3 \mathrm{~cm} \times 6 \mathrm{~cm}$. Thermal aging was performed at $60,70,80$, and $90{ }^{\circ} \mathrm{C}$ for $2-185$ days in a convection oven. Crosslink densities of the samples before and after the thermal aging were measured by swelling method. Organic additives in the samples were removed by extracting with THF and $n$-hexane for 3 and 2 days, respectively, and they were dried for 2 days at room temperature. The weights of the organic materials-extracted samples were measured. They were soaked in toluene for 2 days and the weights of the swollen samples were measured. The swelling ratio $(\mathrm{Q})$ was calculated by the equation $(1)^{12}$

$$
\mathrm{Q}=\left(\mathrm{W}_{\mathrm{s}}-\mathrm{W}_{\mathrm{u}}\right) / \mathrm{W}_{\mathrm{u}}
$$

where $\mathrm{W}_{\mathrm{s}}$ and $\mathrm{W}_{\mathrm{u}}$ are weights of the swollen and unswollen

Scheme 1. Chemical structures of EPDM, IIR, and BIIR. 
samples. In general, the reciprocal swelling ratio (1/Q) was used as the apparent crosslink density. Experiments were carried out three times and were then averaged.

Organic materials remained in the aged samples were extracted with THF and analyzed with gas chromatography/mass spectrometry (GC/MS). GC/MS chromatograms and mass spectra of the extracted materials were acquired with $6890 \mathrm{~N} / 5987$ GC/MS of Agilent Co. DP-5MS capillary column (length 30 $\mathrm{m})$ was used. Injector temperature of the $\mathrm{GC}$ was $250{ }^{\circ} \mathrm{C}$. The GC oven temperature program was as follows. (1) The initial temperature was $70{ }^{\circ} \mathrm{C}$ and kept for $3 \mathrm{~min}$. (2) The temperature was increased from 70 to $300{ }^{\circ} \mathrm{C}$ at a rate of $10{ }^{\circ} \mathrm{C} / \mathrm{min}$.

\section{Results and discussion}

KEP 350 (EPDM) has ethylidene norbornene (ENB) as diene of $8 \mathrm{wt} \%(2.3 \mathrm{~mol} \%)$ and $56.5 \mathrm{wt} \%$ of ethylene content. Isoprene content of Butyl 268 (IIR) is $2.1 \mathrm{wt} \%$ (1.7 mol\%), while functional bromine $\left(\mathrm{C}_{5} \mathrm{H}_{7} \mathrm{Br}\right)$ content of Bromobutyl 2222 (BIIR) is $2.7 \mathrm{wt} \%$ (1.03 mol\%). Thus, Butyl 268 has more isoprene units than Bromobutyl 2222. Ethylene and propylene units of EPDM and isobutene units of IIR and BIIR do not have any allylic hydrogens to participate in sulfur crosslinking reactions. The numbers of allylic hydrogens of one $\mathrm{ENB}$, isoprene, and brominated isoprene units are 6, 7, and 6 , respectively, as shown in Scheme 1. By multiplying them by the mole fraction, the ratios of allylic hydrogens of EPDM, IIR, and BIIR were calculated. The ratios are 13.8, 11.9, and 6.2 for EPDM, IIR, and BIIR, respectively.

Crosslink denisty change $\left(\Delta \mathrm{X}_{\mathrm{c}}\right)$ was calculated by the equation (2)

$$
\Delta \mathrm{X}_{\mathrm{c}}=100 \times\left\{\left(1 / \mathrm{Q}_{\mathrm{f}}\right)-\left(1 / \mathrm{Q}_{\mathrm{i}}\right)\right\} /\left(1 / \mathrm{Q}_{\mathrm{i}}\right)
$$

where $\left(1 / \mathrm{Q}_{\mathrm{i}}\right)$ and $\left(1 / \mathrm{Q}_{\mathrm{f}}\right)$ are the apparent crosslink densities of the specimens before and after the thermal aging. The experimental results were arranged by dividing the results with short- and long-term agings as shown in Figures 1 - 4. The maximum crosslink density changes for the aging time of 185 days were less than $25,30,40$, and $60 \%$ for the aging temperature of $60,70,80,90{ }^{\circ} \mathrm{C}$, respectively. The values are relatively much lower than those of general $\mathrm{R}$ group rubbers such as NR, BR, SBR, and NBR. ${ }^{2-10}$ The crosslink densities of the EPDM composite increased after thermal aging irrespective of the aging temperatures and the aging times. The crosslink densities of the BIIR composite also increased after thermal aging except the long-term thermal aging at high temperatures. The increased crosslink densities of sulfur-cured rubber vulcanizates by thermal aging can be explained with the formations of new crosslinks by free curative residues such as elemental sulfur, cure accelerator residues, and zinc complexes remained in a sample. ${ }^{4,6,27,28}$ Especially, free sulfur remained in a vulcanizate reacts well with rubber chains and makes new crosslinks. ${ }^{4}$ Combination reactions between pendent sulfide groups terminated by an accelerator residue also enhance the crosslink density. ${ }^{6,27,28}$ Zinc complex, which is cosisted of zinc oxide, fatty acids, cure accelerators, and sulfur, activates crosslinking reactions, and it makes the cure rate faster and enhances the crosslink density.

The crosslink densities of the IIR composite decreased for the initial aging period and then increased as shown in Figures 1 - 4. These decreased crosslink densities of the IIR composite were observed for the thermal aging at relatively low temperatures of 60 and $70{ }^{\circ} \mathrm{C}$. The decreased crosslink density signifies that dissociation of the existing crosslinks overcame formation of new crosslinks. In order to make new crosslinks, isoprene units of different two rubber chains of IIR should be neighbored. However, since the IIR only has $1.7 \mathrm{~mol} \%$ isoprene units, the chance to meet the two isoprene units may be very low. In addition, the isoprene unit of IIR can be sterically hindered by two methyl groups of the isobutene unit. On the other hand, polysulfides can be easily dissociated by heating. Thus, the crosslink density of the IIR composite can be decreased by thermal aging. As the aging time elapses, crosslinking-related chemicals such as zinc complexes, curative residues, and sulfur can gather around the isoprene units and participate in crosslinking reactions because diene units $(\mathrm{C}=\mathrm{C})$ and the crosslinking-related chemicals are relatively polar. Gathering of the crosslinking-related chemicals and crosslinking reactions by them will be more activated by increasing the temperature. For the EPDM and BIIR composites, the crosslink densities were not decreased by the thermal aging. This can be explained with the side diene group of EPDM and the role of bromine as a ligand in a zinc complex of BIIR. Since the dienes (ENB) of EPDM are not a backbone of the polymer and are the side groups, they will not be sterically hindered. In addition, the allylic hydrogen content ratio of the EPDM is higher than that of the IIR as discussed above. Thus, for the initial aging period, the crosslink density of the EPDM composite will increase by formation of new crosslinks. For the BIIR composite, bromaine of BIIR can play a role of a ligand in a zinc complex as shown in Scheme 2. When zinc complexes are activated by bromine, the activation energy for crossinking reactions decreases. Thus, formation of new crosslinks will be activated although the allylic hydrogen content ratio of the BIIR is lower than that of the IIR as discussed previously.

For the short-term thermal aging, the $\Delta \mathrm{X}_{\mathrm{c}} \mathrm{s}$ of the EPDM and BIIR composites were larger than those of the IIR one irrespective of the aging temperatures. This may be also due to the role of bromine as a ligand in a zinc complex of BIIR and the side diene group of EPDM. The relative order of the 


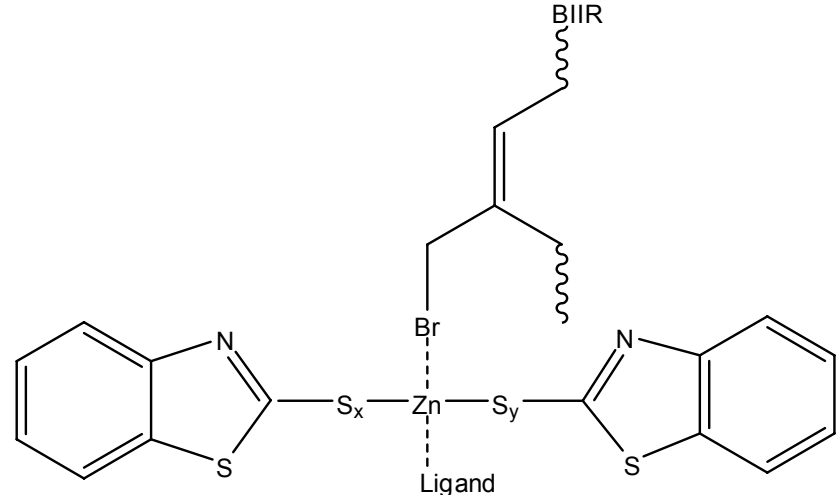

Scheme 2. Structures of zinc complex including bromine of BIIR.
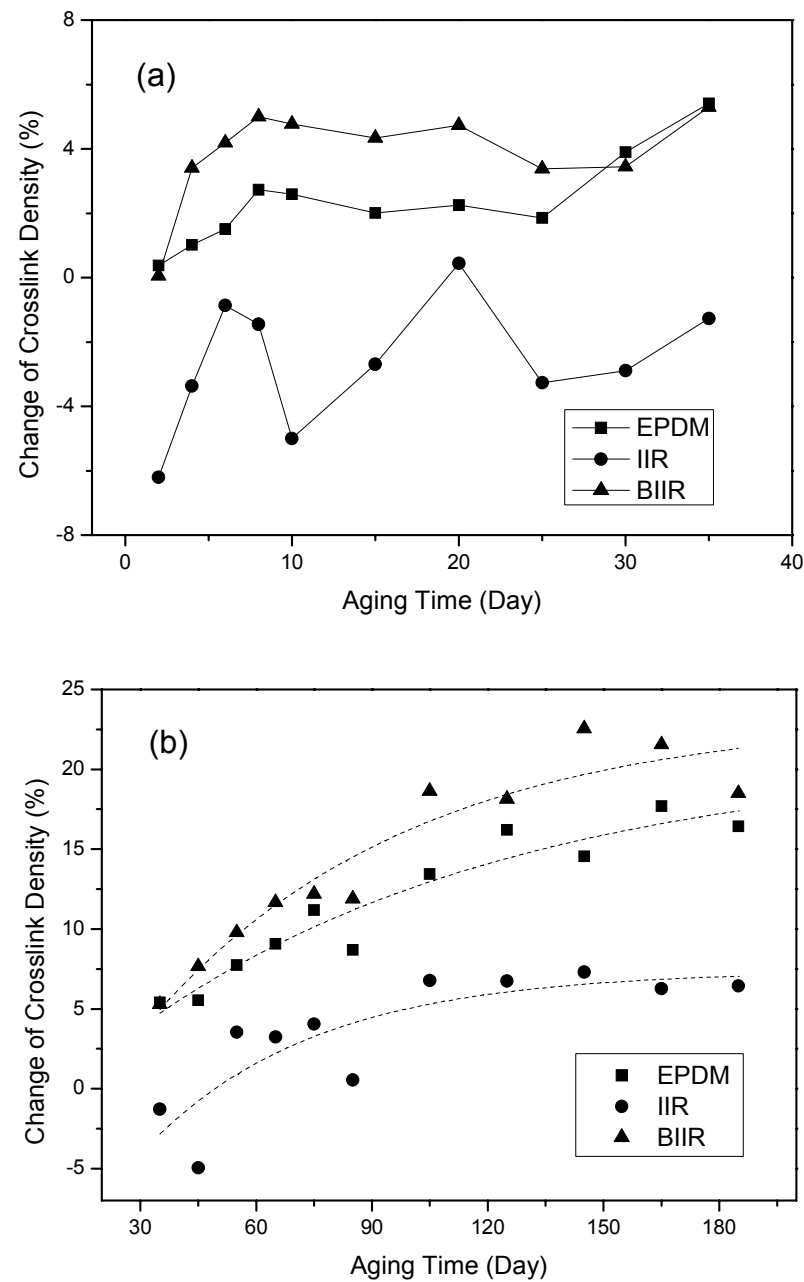

Figure 1. Variations of the crosslink density changes of the rubber composites by short-term (a) and long-term (b) thermal aging at $60{ }^{\circ} \mathrm{C}$ with the aging time. The squares, circles, and triangles indicate the EPDM, IIR, and BIIR specimens, respectively.
$\Delta \mathrm{X}_{\mathrm{c}} \mathrm{s}$ of the BIIR composite aged for a short time notably varied with the aging temperature. For the short-term thermal aging at $60{ }^{\circ} \mathrm{C}$, the $\Delta \mathrm{X}_{\mathrm{c}} \mathrm{S}$ of the BIIR composite were larger than those of the EPDM one as well as those of the IIR one as shown in Figure 1(a). The $\Delta \mathrm{X}_{\mathrm{c}} \mathrm{s}$ of the BIIR and EPDM composites aged at $70{ }^{\circ} \mathrm{C}$ for a short time were nearly the same as shown in Figure 2(a). For the short-term thermal aging at 80 and $90{ }^{\circ} \mathrm{C}$, the $\Delta \mathrm{X}_{\mathrm{c}}$ s of the BIIR composite were smaller than those of the EPDM one and the difference became bigger as shown in Figures 3(a) and 4(a). This can be explained with the reduction of the favorability of the role of bromine as a ligand in a zinc complex of BIIR and the enhancement of the crosslinking reaction of the side diene group of EPDM by increasing the aging temperature. The zinc complexes can be activated by binding of bromine $(\mathrm{Br})$ to zinc ion $\left(\mathrm{Zn}^{2+}\right)$
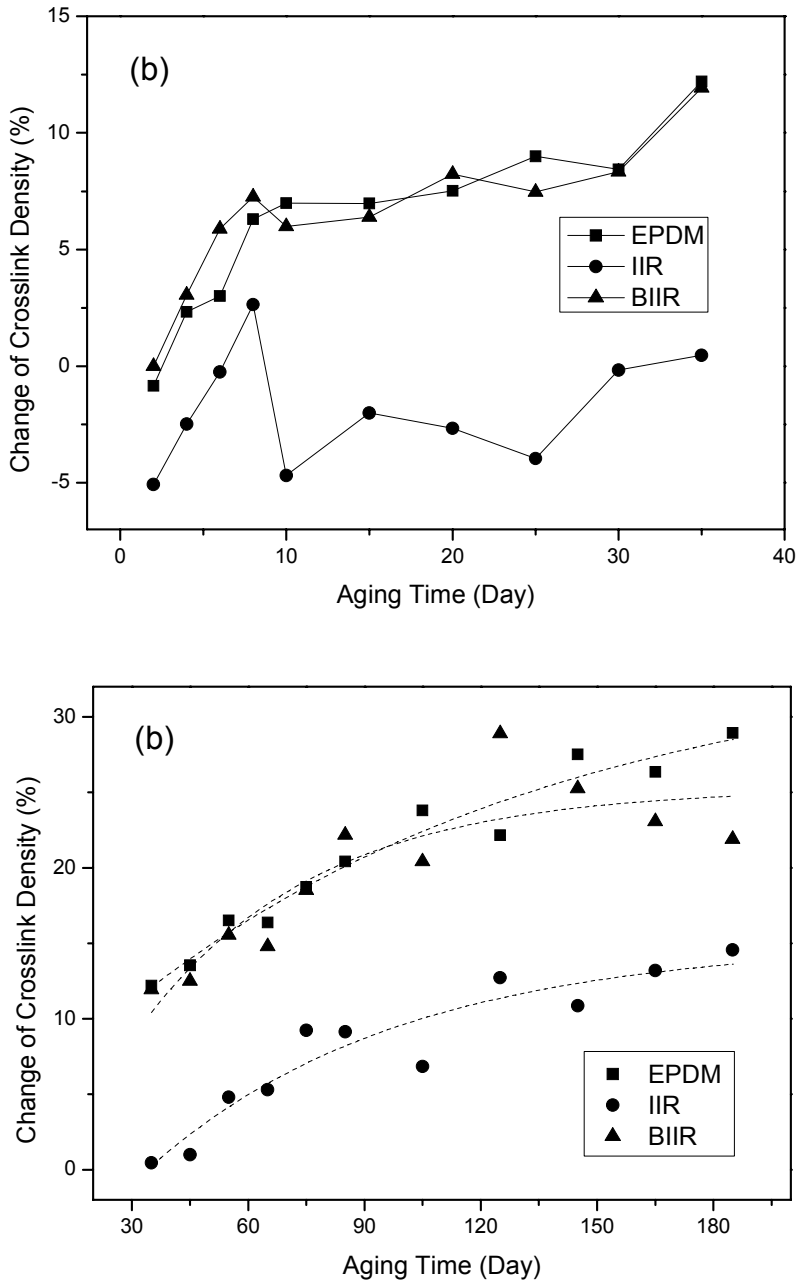

Figure 2. Variations of the crosslink density changes of the rubber composites by short-term (a) and long-term (b) thermal aging at $70{ }^{\circ} \mathrm{C}$ with the aging time. The squares, circles, and triangles indicate the EPDM, IIR, and BIIR specimens, respectively. 

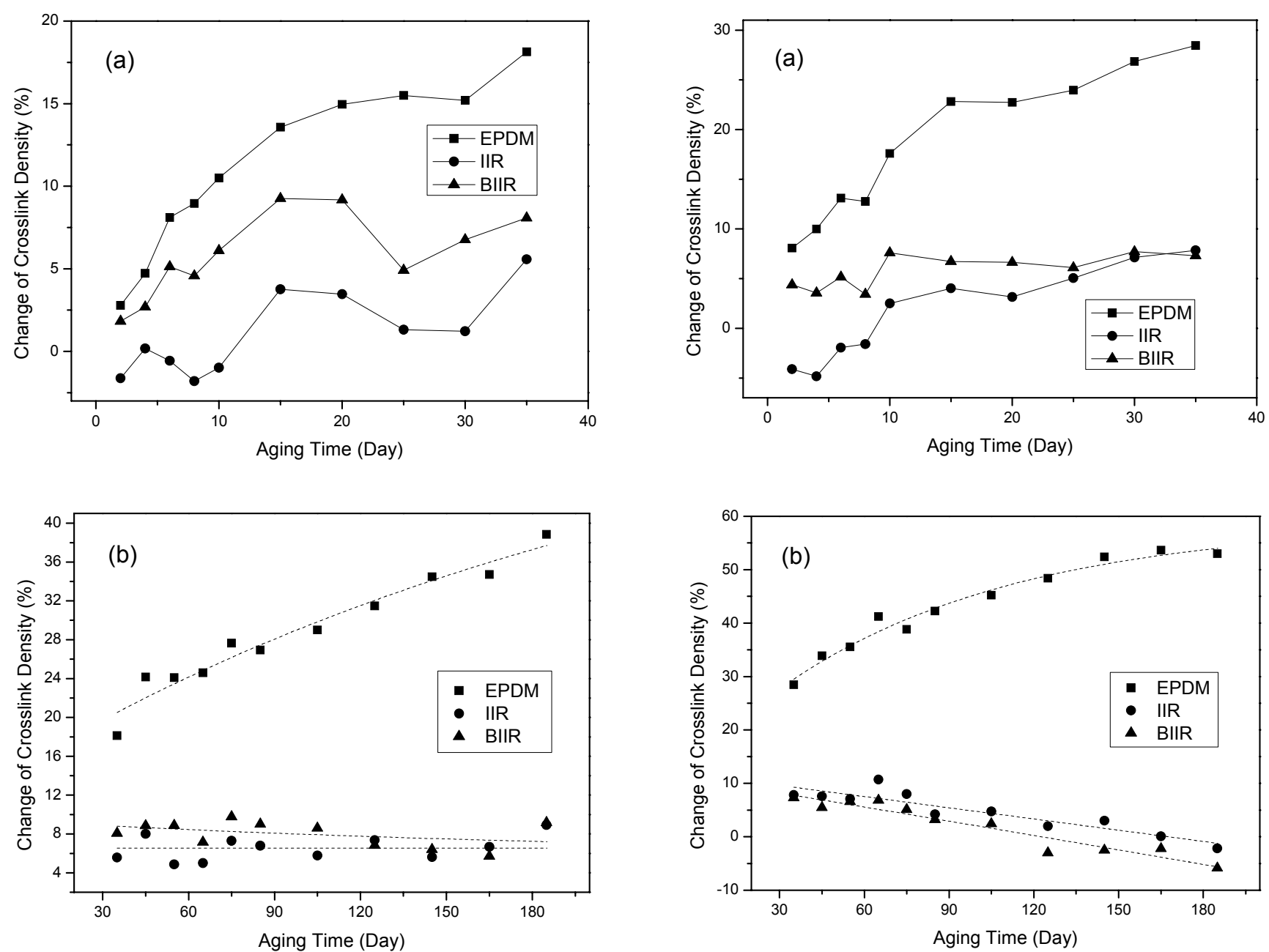

Figure 3. Variations of the crosslink density changes of the rubber composites by short-term (a) and long-term (b) thermal aging at $80{ }^{\circ} \mathrm{C}$ with the aging time. The squares, circles, and triangles indicate the EPDM, IIR, and BIIR specimens, respectively.

and the activation energy for crossinking reactions decreases. Thus, the crossinking reactions will be more activated by binding of $\mathrm{Zn}---\mathrm{Br}$. However, if the temperature becomes higher, the binding strength of $\mathrm{Zn}---\mathrm{Br}$ will be weaken. Hence, at high temperatures, the role of bromine as a ligand in a zinc complex of BIIR will be reduced. On the contrary, the sulfur-crosslinking reactions of the side diene groups of EPDM will be more activated by increasing the temperature.

For the themal aging at $60{ }^{\circ} \mathrm{C}$ (Figure 1), the $\Delta \mathrm{X}_{c}$ s of BIIR composite were larger than those of the EPDM and IIR ones. For the themal aging at $70{ }^{\circ} \mathrm{C}$ (Figure 2), the $\Delta \mathrm{X}_{\mathrm{c}} \mathrm{s}$ of the BIIR composite were larger than those of the IIR, while the $\triangle \mathrm{X}_{\mathrm{c}} \mathrm{S}$ of the BIIR and EPDM composites were nearly the same. For the themal aging at 80 an $90{ }^{\circ} \mathrm{C}$ (Figures 3 and 4), the $\Delta \mathrm{X}_{\mathrm{c}}$ s of the BIIR composite were smaller than those

Figure 4. Variations of the crosslink density changes of the rubber composites by short-term (a) and long-term (b) thermal aging at $90{ }^{\circ} \mathrm{C}$ with the aging time. The squares, circles, and triangles indicate the EPDM, IIR, and BIIR specimens, respectively.

of the EPDM one. The larger $\Delta \mathrm{X}_{\mathrm{c}} \mathrm{S}$ of BIIR composite at low temperature of $60{ }^{\circ} \mathrm{C}$ were very interesting because the allylic hydrogen content ratio of BIIR is lower than those of EPDM and IIR. This implies that zinc complexes by binding of bromine remarkably reduced activation energies for crosslinking reactions. However, by increasing the aging temperature, the binding strength of $\mathrm{Zn}---\mathrm{Br}$ will be weakened and the effect on the activation energy reduction will be decreased. Due to the weakening of $\mathrm{Zn}$---Br binding strength, degree of the $\Delta \mathrm{X}_{\mathrm{c}} \mathrm{S}$ of the BIIR composite at high temperatures was small. For the long-term thermal aging at $90{ }^{\circ} \mathrm{C}$, the $\Delta \mathrm{X}_{\mathrm{c}} \mathrm{S}$ of the BIIR composite were even smaller than those of the IIR one. Another reason about the smaller $\Delta \mathrm{X}_{\mathrm{c}}$ s of the BIIR composite is the steric hindrance by bromine atom besides of the weakening of $\mathrm{Zn}$---Br binding strength. Atomic radius 


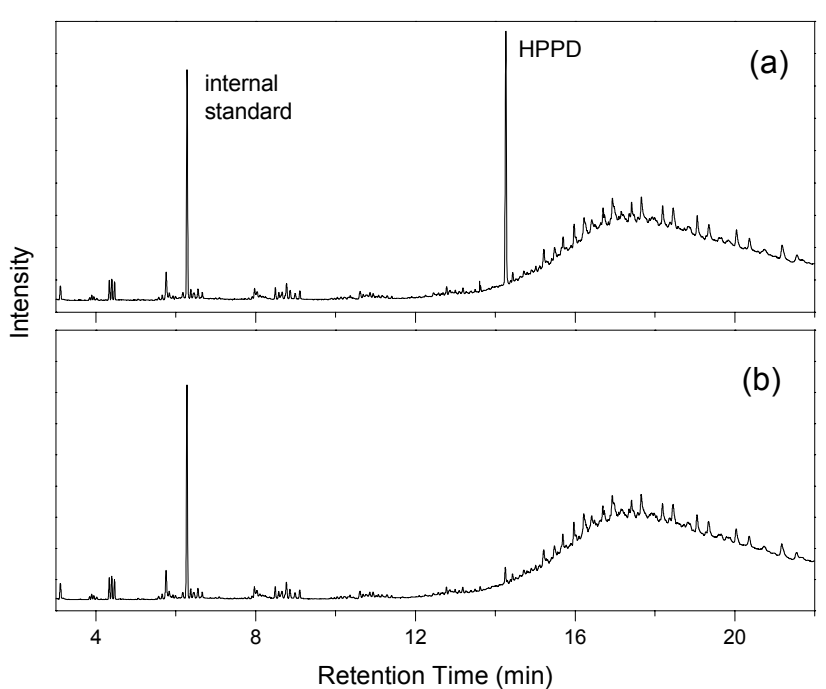

Figure 5. GC/MS TIC chromatograms of the organic materials extracted with THF from the EPDM composite aged at 90 ${ }^{\circ} \mathrm{C}$ for 5 (a) and 35 (b) days.

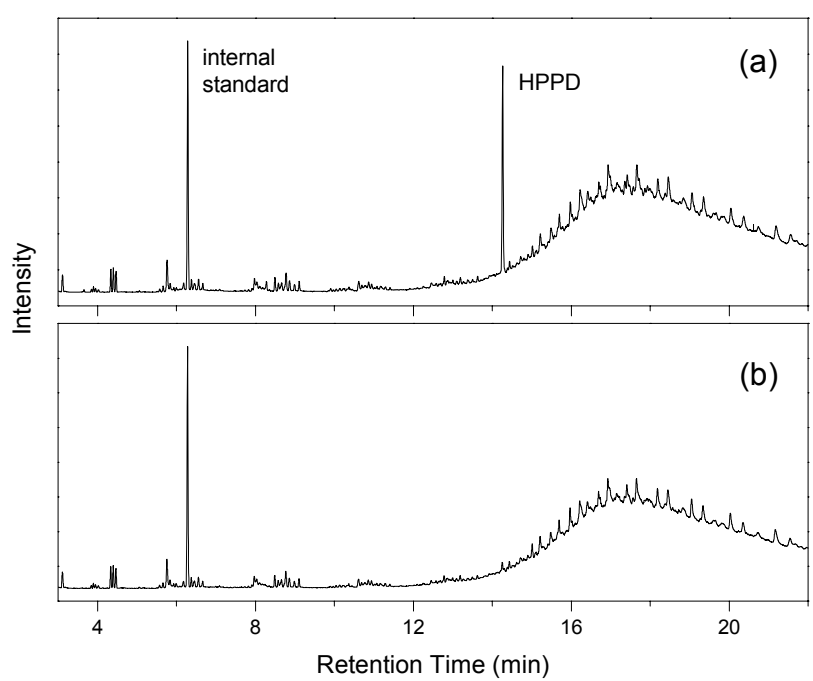

Figure 6. GC/MS TIC chromatograms of the organic materials extracted with THF from the IIR composite aged at $90{ }^{\circ} \mathrm{C}$ for 5 (a) and 35 (b) days.

of bromine atom is much bigger than those of hydrogen and carbon atoms. Atomic radii of hydrogen, carbon, and bromine atoms are 37, 77, and $114 \mathrm{pm}$, respectively. Since $\mathrm{Br}$ atom in BIIR is neighbored around allylic hydrogens and is relatively much bigger than hydrogen and carbon atoms, allylic hydrogens will be sterically hindered by $\mathrm{Br}$ atom and formation of new crosslinks will be prevented. By increasing the temperature, rotation of the $\mathrm{Br}$ atom and the steric hindrance might be more activated.

For the long-term themal aging of the IIR and BIIR compo-

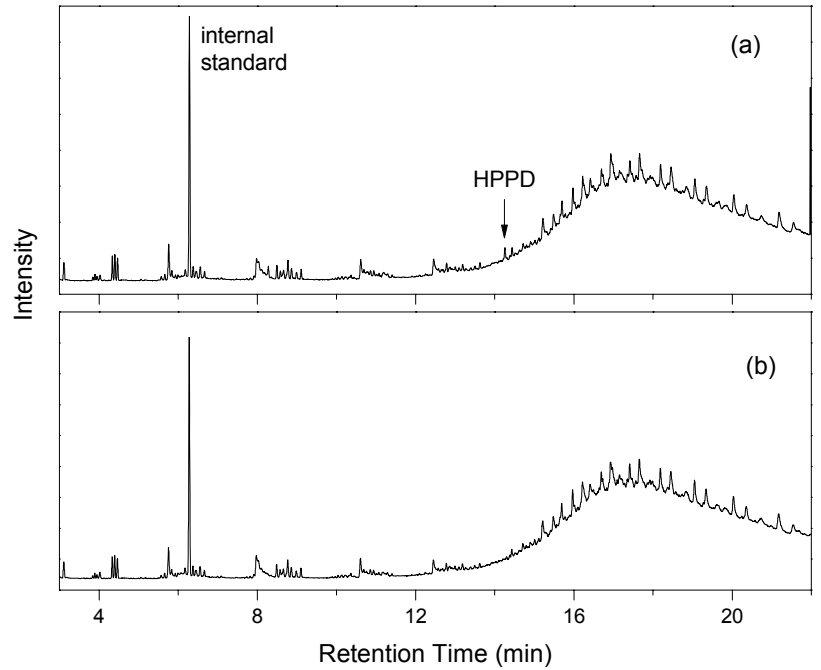

Figure 7. GC/MS TIC chromatograms of the organic materials extracted with THF from the BIIR composite aged at $90{ }^{\circ} \mathrm{C}$ for 5 (a) and 35 (b) days.

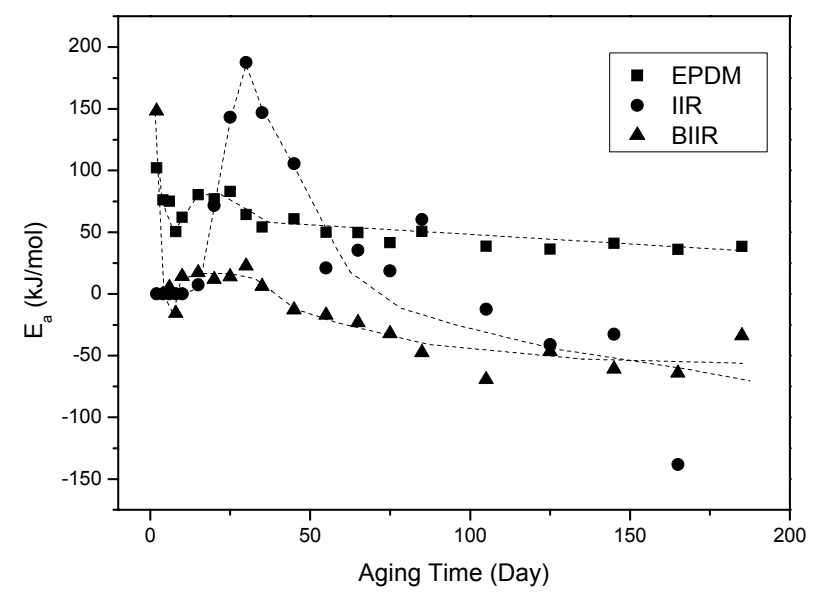

Figure 8. Variations of the activation energies for the crosslink density changes by thermal aging as a function of the aging time. The squares, circles, and triangles indicate the EPDM, IIR, and BIIR specimens, respectively.

sites at 80 and $90{ }^{\circ} \mathrm{C}$ (Figures 3(b) and 4(b)), the $\Delta \mathrm{X}_{\mathrm{c}} \mathrm{s}$ decreased as the aging time elapsed. On the contrary, the $\Delta \mathrm{X}_{\mathrm{c}} \mathrm{s}$ of the IIR and BIIR composites aged at 80 an $90{ }^{\circ} \mathrm{C}$ for a short time incresed by increasing the aging time as shown in Figures 3(a) and 4(a). The decreasing trends of the $\Delta \mathrm{X}_{\mathrm{c}} \mathrm{s}$ of the IIR and BIIR composites aged at 80 an $90{ }^{\circ} \mathrm{C}$ for a long time were very interesting because most of common rubber vulcanizates showed increasing $\Delta \mathrm{X}_{\mathrm{c}}$ trends with the aging time irrespective of the aging temperatures. ${ }^{5-7}$ The crosslink densities of the IIR and BIIR composites after thermal aging at $90{ }^{\circ} \mathrm{C}$ for a long time above 100 days also decreased as 
shown in Figure 4(b). This may be due to the chain scissions of the IIR and BIIR by oxidation. HPPD was used as an antidegranant to protect rubber chains from dissociation by oxidation. When HPPD is not sufficiently on the sample surface, some rubber chains can be oxidated and dissociated. IIR and BIIR have carbon-carbon double bond $(\mathrm{C}=\mathrm{C})$ backbones of the isoprene unit. If antidegradants do not exist in a rubber article, the $\mathrm{C}=\mathrm{C}$ backbones of rubber chains are degraded by ozone and oxygen. Over a longer period of time, the free radical reactions can lead either to chain scission giving a softer material or to higher network density resulting in a harder or more brittle material. ${ }^{29}$ The greater content of EPDM in its blends with butyl rubber provides a certain resistance against oxidation. ${ }^{30}$ For EPDM, there is no carbon-carbon double bond $(\mathrm{C}=\mathrm{C})$ backbone. Amounts of HPPD remained in the rubber composites were notably decreased as the aging time elapsed and as the aging temperature increased by migration to the surface and evaporation. Amounts of HPPD remained in the rubber samples after thermal aging at $90{ }^{\circ} \mathrm{C}$ for 35 days were negligible as shown in Figures. ${ }^{5-7}$

Activation energies for the $\Delta \mathrm{X}_{\mathrm{c}} \mathrm{s}$ by thermal aging were obtained from the Arrhenius plot of $\ln k$ vs $1 / T$, where $k$ is the $\Delta \mathrm{X}_{\mathrm{c}}$ and $T$ is the aging temperature, to compare the thermal aging behaviors of the EPDM, IIR, and BIIR composites. The activation energies varied with the aging time as shown in Figure 8. This implies that states of the samples depend on the aging time. Density and type of the crosslinks are changed hourly because new crosslinks are formed and the existing crosslinks are dissociated by thermal aging. And the kinds and amounts of curative residues remained in the sample are also hourly changed. The activation energies for the crosslink density changes of the rubber composites on the whole tended to decrease as the aging time elapsed. The activation energy curves of the EPDM and BIIR composites showed one maximum and one minimum points. At the initial period of aging, remained crosslinking-related chemicals can gather and participate in crosslinking reactions. This may reduce the activation energy. The increasing activation energy after the minimum point may be because consumption of the crosslinking-related chemicals overcomes gathering of the crosslinking-related chemicals as well as formation of new crosslinking-related chemicals. The activation energies of the EPDM composite were higher than those of the BIIR one. This may be due to the role of $\mathrm{Br}$ atom as a ligand in a zinc complex. Activation of a zinc complex in a rubber vulcanizate having a sulfur cure system reduces the activation energy of vulcanization. The activation energy of the IIR composite remarkly increased and then decreased.

\section{Conclusions}

The crosslink densities of the EPDM composite increased after thermal aging irrespective of the aging temperatures and the aging times, while those of the BIIR composite also increased after thermal aging except the long-term thermal aging at high temperatures. However, the crosslink densities of the IIR composite decreased for the initial aging period and then increased. The decreased crosslink densities of the IIR composite for the initial aging period may be due to the steric hindrance for the crosslinking reactions by the two methyl groups of isobutene unit and the small content of isoprene units. The $\triangle \mathrm{X}_{\mathrm{c}} \mathrm{s}$ of the BIIR composite aged at $60{ }^{\circ} \mathrm{C}$ were larger than those of the EPDM one, whereas those aged at 80 and 90 ${ }^{\circ} \mathrm{C}$ were smaller than those of the EPDM composite. This was due to the weakening of $\mathrm{Zn}$---Br binding strength and enhancement of the steric hindrance for the crosslinking reactions by bromine atom. The $\Delta \mathrm{X}_{\mathrm{c}} \mathrm{s}$ of the IIR and BIIR composites aged at 80 and $90{ }^{\circ} \mathrm{C}$ for a long time decreased as the aging time elapsed. This was due to the lack of antidegradants in the rubber samples and the chain scissions by oxidation. The activation energies of the EPDM composite were higher than those of the BIIR one due to the role of $\mathrm{Br}$ atom as a ligand in a zinc complex. The activation energy of the IIR composite remarkly increased and then decreased.

\section{Acknowledgements}

This research was supported by a grant from the Fundamental R\&D Program for Core Technology of Materials funded by the Ministry of Knowledge Economy, Republic of Korea.

\section{References}

1. S.-S. Choi and J.-C. Kim, "Chlorine effect on thermal aging behaviors of BR and CR composites", Bull. Kor. Chem. Soc., 31, 2613 (2010).

2. S.-S. Choi, "Influence of thermal aging on change of crosslink density and deformation of natural rubber vulcanizates", Bull. Kor. Chem. Soc., 21, 628 (2000).

3. C.-S. Woo and S.-S. Choi, "Effects of thermal aging on properties and life-time prediction of NBR and EPDM vulcanizates", Elastomer, 40, 119 (2005).

4. S.-S. Choi, S.-H. Ha, and C.-S. Woo, "Thermal aging behaviors of rubber vulcanizates cured with single and binary cure systems", Bull. Kor. Chem. Soc., 27, 429 (2006).

5. S.-S. Choi, J.-C. Kim, and C.-S. Woo, "Accelerated thermal aging behaviors of EPDM and NBR vulcanizates", Bull. Kor. Chem. Soc., 27, 936 (2006).

6. S.-S. Choi and J.-C. Kim, "Influence of the 1,2-unit content of SBR and filler systems on thermal aging behaviors of SBR composites", J. Ind. Eng. Chem., 13, 950 (2007). 
7. S.-S. Choi, J.-C. Kim, S. G. Lee, and Y. L. Joo, "Influence of the cure systems on long time thermal aging behaviors of NR composites", Macromol. Res., 16, 561 (2008).

8. S.-S. Choi, J. Jose, M.-Y. Lyu, Y.-I. Huh, B. H. Cho, and C. Nah, "Influence of filler and cure systems on thermal aging resistance of natural rubber vulcanizates under strained condition", J. Appl. Polym. Sci., 118, 3074 (2010).

9. S.-S. Choi and J.-C. Kim, "Influence of reinforcing systems on thermal aging behaviors of NR composites", Elast. Comps., 46, 237 (2011).

10. S.-S. Choi and J.-C. Kim, "Lifetime prediction and thermal aging behaviors of SBR and NBR composites using crosslink density changes", J. Ind. Eng. Chem., 18, 1166 (2012).

11. S.-S. Choi, "Influence of thermally aged resoles on properties of resole-cured butyl rubber vulcanizates", Kor. Polym. J., 7, 30 (1999).

12. S.-S. Choi, K.-C. Nam, S. W. Ko, and J. M. Kim, "Properties of butyl rubber vulcanizates cured by different type resoles", Kor. Polym. J., 7, 172 (1999).

13. N. J. Morrison and M. Porter, "Temperature effects on the stability of intermediates and crosslinking in sulfur vulcanization", Rubber Chem. Technol., 57, 63 (1984).

14. C. H. Chen, J. L. Koenig, J. R. Shelton, and E. A. Collins, "Characterization of the reversion process in accelerated sulfur curing of natural rubber", Rubber Chem. Technol., 54, 734 (1981).

15. S.-S. Choi, "Bond dissociation of sulfur crosslinks in IR and BR vulcanizates using semi-empirical calculations", Kor. Polym. J., 5, 39 (1997).

16. R. W. Layer, "Recuring vulcanizates. I. A novel way to study the mechanism of vulcanization", Rubber Chem. Technol., 65, 211 (1992)

17. S.-S. Choi, "Change of crosslink density of sulfur-cured NR vulcanizates by thermal aging", Kor. Polym. J., 7, 108 (1999).

18. S.-S. Choi, "Influence of rubber composition on change of crosslink density of rubber vulcanizates with EV cure system by thermal aging", J. Appl. Polym. Sci., 75, 1378 (2000).

19. S.-S. Choi, "Influence of internal strain on change of crosslink density in rubber vulcanizates", Polym. Int., 50, 107 (2001).

20. S.-S. Choi, D.-H. Han, S.-W. Ko, and H. S. Lee, "Thermal aging behaviors of elemental sulfur-free polyisoprene vulcanizates", Bull. Kor. Chem. Soc., 26, 1853 (2005).

21. S.-S. Choi and D.-H. Han, "Recovery prediction of thermally aged chloroprene rubber composite using deformation test", J. Appl. Polym. Sci., 110, 3560 (2008).

22. S.-S. Choi and D.-H. Han, "Comparison of recovery behaviors of thermally aged SBR composite from compressed and circular deformations", Thermochim. Acta, 490, 8 (2009).

23. S.-S. Choi and D.-H. Han, "Strain effect on recovery behaviors from circular deformation of natural rubber vulcanizate", J. Appl. Polym. Sci., 114, 935 (2009).

24. R. P. Brown and T. Butler, Natural ageing of rubber. Changes in physical properties over 40 years, RAPRA Technology Ltd. (2000).

25. R. P. Brown, T. Butler, and S. W. Hawley, Ageing of rubber. Accelerated heat ageing test results, RAPRA Technology Ltd. (2001).

26. S.-S. Choi, K.-C. Nam, S. W. Ko, and J. M. Kim, "Properties of butyl rubber vulcanizates cured by different type resoles", Kor. Polym. J., 7, 172 (1999).

27. M. H. S. Gradwell and W. J. McGill, "Sulfur vulcanization of polyisoprene accelerated by benzothiazole derivatives. III. The reaction of 2-bisbenzothiazole-2,2-disulfide with sulfur and $\mathrm{ZnO}$ in polyisoprene", J. Appl. Polym. Sci., 61, 1131 (1996).

28. M. H. S. Gradwell and W. J. McGill, "Sulfur vulcanization of polyisoprene accelerated by benzothiazole derivatives. IV. The reaction of polyisoprene with $\mathrm{N}$-cyclohexylbenzothiazole sulfenamide, sulfur, and zinc oxide", J. Appl. Polym. Sci., 61, 1515 (1996).

29. B. Stenberg, L.-O. Peterson, F. Bjork, and P. Flink, "Effect of butyl rubber coating on accelerated aging of natural rubber", Rubber Chem. Technol., 59, 70 (1986).

30. T. Zaharescu, S. Jipa, M. Giurginca, and C. Podina, "Evaluation of compatibility of EPDM and butyl rubber-II. Thermal and radiation stability", Polym. Deg. Stab., 62, 569 (1998). 